\section{Hantavirus en Chile: Nuevos roedores con potencial importancia epidemiológica}

\section{Hantavirus in Chile: New rodents with potential epidemiological importance}

\section{Sr. Editor:}

El virus Andes (ANDV) es considerado el principal agente etiológico en América del Sur entre todos los hantavirus descritos, produciendo el Síndrome Cardiopulmonar por Hantavirus (SCPH) con una tasa de mortalidad que ha fluctuado históricamente entre $30-50 \%$.

En Chile, Oligoryzomys longicaudatus (conocido como colilargo) es considerado el reservorio primario de ANDV ${ }^{1}$. Sin embargo, se han reportado cuatro otras especies nativas en Chile de roedores sigmodontinos seropositivos a ANDV: Abrothrix olivacea, Abrothrix longipilis, Phyllotis darwini y Loxodontomys micropus ${ }^{2}$. Además, un estudio en la Región de Aysén, reportó ejemplares asignados a Abrothrix sanborni como seropositivos a ANDV (http://www2.sag.gob.cl/Pecuaria/ bvo/noviembre_2004/1.htm), aunque no hemos encontrado registros subsecuentes en esta especie en publicaciones indexadas.

Las nuevas investigaciones en taxonomía de sigmodontinos en Chile tienen implicancias en la importancia epidemiológica, particularmente en hantavirus. Por ejemplo, para O. longicaudatus, se han descrito tres subespecies, siendo la más austral O. l. magellanicus que habitaría la Patagonia y Tierra del Fuego ${ }^{3}$. Sin embargo, su status taxonómico está aún en debate. Aunque algunos autores consideran que Oligoryzomys magellanicus es una especie válida ${ }^{4}$ y que estaría en simpatría (distribuida en la misma área geográfica) con O. longicaudatus en la Patagonia y Tierra del Fuego, evidencias de diversas bases de datos (e.j. cromosomas, secuenciación de $\mathrm{ADN}$, morfología) sobre extensos muestreos en el área austral de Chile (y Argentina) ratifican la existencia de $O$. longicaudatus en esta área y otras islas. Lo anterior impacta directamente en la epidemiología del ANDV dado que se ha reportado individuos seropositivos en áreas cercanas a Fuerte Bulnes ${ }^{5}$ y otras áreas de la Patagonia (datos no publicados).

Recientemente fue descrita la especie Abrothrix hirta ${ }^{6}$, habitando desde los $35^{\circ} S$ hasta el norte de Tierra del Fuego, restringiendo a la especie $A$. longipilis entre los $30^{\circ}$ a $34^{\circ} \mathrm{S}$ aproximadamente (en la franja costera de matorrales mediterráneos). Dado este reordenamiento taxonómico, los registros de roedores seropositivos a ANDV al sur de los $35^{\circ} \mathrm{S}$ y que han sido asignados a A. longipilis, corresponderían a A. hirta. De acuerdo a esta nueva clasificación, los ejemplares que habitan al norte de los $35^{\circ} \mathrm{S}$ corresponderían efectivamente a $A$. longipilis.
De los estudios actualmente disponibles se desprende que existirían cuatro especies del género Abrothrix detectados seropositivos para ANDV: A. olivacea, A. longipilis, A. hirta y A. sanborni. Además, habría que agregar a la discusión la incorporación de un nuevo sigmodontino en Chile, Abrothrix manni, que habitaría en la región de los Ríos y de los Lagos entre los $39^{\circ}$ a los $43^{\circ} \mathrm{S}$ aproximadamente. En esta área hemos registrado individuos seropositivos a ANDV (datos no publicados) que fueron preliminarmente designados a A. olivacea y A. longipilis. Nuevos análisis de los ejemplares capturados en esa zona se requieren para confirmar si $A$. manni es una especie seropositiva a ANDV.

En base a los antecedentes señalados, actualmente en Chile habría evidencia de al menos cinco especies de roedores nativos que han resultado seropositivos a ANDV, correspondiendo a: O. longicaudatus, A. olivacea, A. longipilis, Phyllotis darwini y Loxodontomys micropus. A éstas especies se podrían agregar A. sanborni y A. manni, para las que se requieren estudios más detallados en taxonomía y metodologías asociadas a la detección de ejemplares seropositivos a ANDV. Dada la evidencia expuesta más arriba, sugerimos que la especie $A$. hirta debiera ser incorporada a la lista de los roedores con importancia epidemiológica en Chile asociadas a la presencia de ANDV. Además, los datos de los muestreos de campo y laboratorio muestran que A. hirta correspondería a la segunda especie con mayor seroprevalencia a ANDV en Chile, desplazando en esta posición a A. longipilis.

A diferencia del reservorio primario O. longicaudatus, para los otros sigmodontinos mencionados no se ha confirmado su rol en el contagio hacia los humanos y que haya resultado en SCPH, por lo que se requieren estudios adicionales para determinar con mayor certeza su importancia en la epidemiología del ANDV. Sin embargo, los datos aquí señalados son fundamentalmente referidos a los análisis de seropositividad. Es decir, se ha confirmado que han desarrollado anticuerpos contra ANDV, pero en muy pocos casos (O. longicaudatus y $A$. hirta) se ha confirmado la presencia de ANDV mediante PCR en los tejidos de los roedores analizados, con el desconocimiento asociado a la capacidad de liberar el virus a través de las heces y secreciones.

El proceso de transmisión horizontal del virus de un hospedador primario a una nueva especie es referido como derrame o "spillover", y su importancia epidemiológica ha sido ampliamente discutida en la literatura, siendo de importancia en lo relacionado a la evolución de nuevos tipos o cepas virales, y a la aparición de nuevas cepas con mayor potencial patogénico. En la naturaleza, los hantavirus están asociados principalmente a una especie de roedor, en los que son mantenidos mediante infección persistente. En Chile, se ha consensuado que existe una sola cepa y 
agente etiológico de hantavirus ${ }^{1}$ (el ANDV), lo que se traduciría en que este virus tendría el potencial de infectar diversas especies, que incluiría a las ya mencionadas junto a otras que han sido reportadas en el lado Argentino. De este modo, ANDV podría ser considerado como un virus que infectaría a un amplio rango de hospedadores, lo que agregaría una nueva particularidad acerca de su mantención, transmisión, y evolución, apartándose de los supuestos que aplican en las propuestas de co-evolución entre los hantavirus y su hospedador.

El rápido progreso de las nuevas herramientas para la clasificación de las especies, ha ido permitiendo mejorar el conocimiento con impacto directo en la taxonomía de los reservorios de patógenos. A esto debe agregarse el actual debate acerca de los criterios para la caracterización de especies y cepas de hantavirus, lo que demuestra que la clasificación taxonómica continua siendo altamente dinámica. Los avances en esta área impactan directamente en la toma de decisiones acerca de la prevención del contagio de enfermedades transmisibles a humanos, y pueden ser fundamentales para la toma de decisiones futuras de las políticas públicas en epidemiología de enfermedades emergentes.

Fernando Torres-Pérez $P h D^{l}$, Dusan Boric-Bargetto $\mathrm{PhD}^{1}$, R. Eduardo Palma Vásquez $P h D^{2}$ ${ }^{1}$ Instituto de Biología, Pontificia Universidad Católica de Valparaíso, Valparaíso, Chile. ${ }^{2}$ Departamento de Ecología, Pontificia Universidad Católica de Chile, Santiago, Chile.

\section{Referencias}

1. Medina RA, Torres-Pérez F, Galeno H, Navarrete M, Vial PA, Palma RE, et al. Ecology, genetic diversity, and phylogeographic structure of Andes virus in humans and rodents in Chile. J Virol 2009; 83: 2446-59.

2. Pavletic C. Hantavirus: Su distribución geográfica entre los roedores silvestres de Chile. Rev Chil Infectol 2000; 17: 186-96.

3. Palma RE, Boric-Bargetto D, Torres-Pérez F, Hernández CE, Yates TL. Glaciation Effects on the Phylogeographic Structure of Oligoryzomys longicaudatus (Rodentia: Sigmodontinae) in the Southern Andes. PLoS ONE7, e32206, doi:10.1371/journal.pone.0032206 (2012).

4. Patton J, Pardiñas UFJ, D'Elía G. Mammals of South America. Vol. 2. Rodents (The University of Chicago Press, Chicago, 2015).

5. Belmar-Lucero S, Godoy P, Ferres M, Vial P, Palma RE. Range expansion of Oligoryzomys longicaudatus (Rodentia, Sigmodontinae) in Patagonian Chile, and first record of Hantavirus in the region. Revista Chilena de Historia Natural 2009; 82: 265-75.

6. Teta P, Pardiñas UFJ. Variación morfológica cualitativa y cuantitativa en Abrothrix longipilis (Cricetidae, Sigmodontinae). Mastozoología Neotropical 2014; 21: 291-309.

Fuente de apoyo financiero: FONDECYT 1110664, 1140929

1130467; Proyecto Anillo CONICYT- PIA ACT1408, Postdoctorado VRIEA-PUCV.

Correspondencia a:

Fernando Torres-Pérez

Av. Universidad 330, Curauma, Valparaíso. 2373223, Chile. fernando.torres@pucv.cl 